\title{
Both structural damage and inflammation of the spine contribute to impairment of spinal mobility in patients with ankylosing spondylitis
}

\author{
Pedro Machado, ${ }^{1,2}$ Robert Landewé, ${ }^{3}$ Jürgen Braun, ${ }^{4}$ Kay-Geert A Hermann, ${ }^{5}$ \\ Daniel Baker, ${ }^{6}$ Désirée van der Heijde ${ }^{2}$
}

${ }^{1}$ Rheumatology, Coimbra University Hospital, Coimbra, Portugal

${ }^{2}$ Rheumatology, Leiden University Medical Center, Leiden, The Netherlands ${ }^{3}$ Rheumatology, University Hospital Maastricht, Maastricht, The Netherlands

${ }^{4}$ Rheumatology,

Rheumazentrum Ruhrgebiet,

Herne, Germany

${ }^{5}$ Radiology, Charité Medical

School, Berlin, Germany

${ }^{6}$ Research and Development,

Centocor Inc, Malvern,

Pennsylvania, USA

\section{Correspondence to}

Professor Désirée van der

Heijde, Department of

Rheumatology, Leiden University

Medical Center, PO Box

9600, Leiden, RC 2300, The

Netherlands;

d.vanderheijde@kpnplanet.nl

Accepted 31 January 2010

\begin{abstract}
Objective To study the relationship between spinal mobility, radiographic damage of the spine and spinal inflammation as assessed by MRI in patients with ankylosing spondylitis (AS).

Methods In this subanalysis of the Ankylosing Spondylitis Study for the Evaluation of Recombinant Infliximab Therapy cohort, 214 patients, representing an $80 \%$ random sample, were investigated. Only baseline data were used. MRI inflammation was assessed by the AS spinal MRI activity (ASspiMRI-a) score, structural damage by the modified Stoke AS Spine Score (mSASSS) and spinal mobility by the linear definition of the Bath Ankylosing Spondylitis Metrology Index (BASMI). Univariate correlations were calculated on baseline values using Spearman rank correlation. Independent associations between the variables of interest were investigated by multivariate linear regression analysis. Associations with clinical disease activity, C-reactive protein, disease duration, age, gender, body mass index and HLA-B27 status were also investigated. Subanalyses were performed according to disease duration.

Results BASMI correlated moderately well with mSASSS (Spearman's $\rho=0.6$ ) and weakly with ASspiMRI-a $(\rho=0.3)$. A best-fit model for BASMI included both mSASSS (regression coefficient $(B)=0.865, p<0.001)$ and ASspiMRI-a $(B=0.236$, $p=0.018$ ). In patients with a disease duration $\leq 3$ years, B was greater for ASspiMRI-a than for mSASSS 10.595 vs 0.380), while in patients with a disease duration $>3$ years B was greater for mSASSS than for ASspiMRI-a (0.924 vs 0.156).
\end{abstract}

Conclusion Spinal mobility impairment in AS is independently determined both by irreversible spinal damage and by reversible spinal inflammation. Spinal mobility impairment is more influenced by spinal inflammation in early disease, and by structural damage in later disease.

\section{INTRODUCTION}

Ankylosing spondylitis (AS) is a chronic progressive inflammatory disorder characterised by inflammatory back pain. Many axial anatomical structures may be involved in AS. Sacroiliitis may occur as well as spondylitis, spondylodiscitis, (spinal) enthesitis and arthritis of the zygoapophyseal, costovertebral and costosternal joints. The disease is characterised by bony fusion of the axial skeleton, which can be detected best on plain radiographs of the spine. ${ }^{1}$

MRI has emerged in recent years as an assessment tool because of its ability to detect inflammation in the sacroiliac joints, the spine and other joints affected by AS. ${ }^{23}$ Only specialised MRI techniques, such as the short $\tau$ inversion recovery (STIR) technique, the T2-weighted gradient-echo sequence after fat suppression (T2-FS) and the T1-weighted turbo spin-echo sequence after administration of contrast agent (gadolinium diethylenetriaminepentaacetic acid (T1/Gd-DTPA)), can detect inflammation with a high level of specificity. ${ }^{24}$ Increased signal on T2-FS and STIR images reflect bone marrow oedema (BMO), while signal enhancement after contrast administration on T1 images reflects hypervascularisation, ${ }^{5}$ both undetectable with conventional radiography. ${ }^{67}$

The association between radiographic damage of the spine and spinal mobility impairment in AS has been unequivocally demonstrated at the group level. ${ }^{8-12}$ However, at the individual level, the association between spinal mobility and radiographic damage is not so strong that spinal mobility can be used as a proxy for radiographic evaluation, ${ }^{12}$ an observation that does not dispute the concept that radiographic damage is associated with decreased spinal mobility. One of the possible explanations for the discordance between the level of spinal mobility impairment and the degree of radiographic damage (eg, patients with severe impairment despite absent or mild radiographic damage) might be that spinal inflammation contributes to spinal mobility impairment in patients with AS. This hypothesis is underlined by the observation in clinical trials that anti-tumour necrosis factor $\alpha$ (TNF $\alpha$ ) therapy may increase spinal mobility after only a few months of treatment, ${ }^{13-15}$ which is in accordance with the suppression of active spinal inflammation as seen on MRI. ${ }^{16-19}$

Taking into account the possibility that spinal inflammation may be an important and potentially reversible factor determining spinal mobility, the aim of this study was to investigate the relationship between spinal mobility, radiographic damage of the spine and spinal inflammation as assessed by MRI in patients with AS, taking other possible factors such as clinical disease activity and gender into account.

\section{PATIENTS AND METHODS \\ Patients with AS}

This study is an investigator-performed subanalysis of the ASSERT (Ankylosing Spondylitis Study for the Evaluation of Recombinant Infliximab Therapy) cohort. ${ }^{14}$ In total 214 patients were 
investigated. Only baseline data were used. These 214 patients were part of a representative $80 \%$ random sample (224 patients) of the ASSERT cohort. Ten patients were excluded from the analysis owing to incomplete radiographic assessment $(n=7)$, incomplete MRI assessment $(n=1)$ or both $(n=2)$. In brief, ASSERT was a double-blind, placebo-controlled clinical trial with infliximab that included patients with AS (according to the modified New York criteria ${ }^{20}$ ) for at least 3 months before screening, with a Bath Ankylosing Spondylitis Disease Activity Index (BASDAI) score $\geq 4$ (range $0-10$ ), and with a spinal pain assessment score $\geq 4$ on a visual analogue scale (range $0-10 \mathrm{~cm}$ ). Patients were excluded from the study if they had total ankylosis of the spine, other inflammatory rheumatic disease or fibromyalgia. Detailed inclusion and exclusion criteria of patients in the ASSERT trial have been described previously. ${ }^{14}$

\section{Disease severity assessments}

Spinal mobility was assessed by the Bath Ankylosing Spondylitis Metrology Index (BASMI), a combined index comprising five measures of spinal mobility and hip involvement in patients with AS. It includes measures of lateral lumbar flexion, tragus-to-wall distance, lumbar flexion, intermalleolar distance and cervical rotation. ${ }^{21} 22$ The Assessment of SpondyloArthritis international Society (ASAS) has adopted the BASMI as one of the measures of their core set for spinal mobility assessment in AS. ${ }^{23}$ The recently proposed linear definition of the BASMI ${ }^{24}$ showed greater sensitivity to change than the BASMI with 3 and 11 grades and was used in this study; moreover, it is more appropriate to statistical analysis. Range is from 0 to 10 , with higher scores representing greater spinal mobility impairment. Disease activity was assessed both by the BASDAI ${ }^{25}$ and by the newly developed ASAS-endorsed Disease Activity Score for use in AS, the ASDAS. ${ }^{26}$ The BASDAI (range 0-10) is a selfadministered, patient-based questionnaire and consists of six questions completed on a $10 \mathrm{~cm}$ visual analogue scale, related to particular symptoms of the disease (fatigue/tiredness, axial pain, pain/swelling in joints, pain/discomfort in entheses, stiffness severity and duration). The following ASDAS formula was used in this study: $(0.121 \times$ back pain $)+(0.058 \times$ duration of morning stiffness $)+(0.110 \times$ patient global $)+(0.073 \times$ peripheral pain/swelling $)+(0.579 \times \ln ($ C-reactive protein $(C R P)+1))$. For both the BASDAI and ASDAS, higher scores represent higher disease activity.

\section{Radiographic assessment and scoring method}

Lateral radiographic views of the cervical and lumbar spine were used and scored according to the modified Stoke AS Spine Score (mSASSS) scoring system. ${ }^{27}$ The total mSASSS is the sum (range 0-72) of the numerical scores for the anterior corners of the cervical spine from the lower border of $\mathrm{C} 2$ to the upper border of $\mathrm{T} 1$, and the anterior corners of the lumbar spine from the lower border of T12 to the upper border of S1 (total of 24 corners). Each vertebral corner is scored as follows: $0=$ normal; $1=$ erosions, sclerosis or squaring; 2 =syndesmophytes; $3=$ bridging syndesmophytes. The mSASSS was chosen by ASAS and the international Outcome Measurement in Rheumatoid Arthritis Clinical Trials as the preferred measure for measuring structural damage and progression in AS. ${ }^{28}$ Patients who had more than three vertebral corners missing were excluded; if $\leq 3$ corners were missing, the mean of the other scoring corners was used for imputation, as previously reported. ${ }^{29}$ Two qualified and well-trained readers who were blinded to the patient's identity and treatment evaluated each radiograph independently. The mean of both readers' scores was used in the analysis.

\section{MRI assessment and scoring method}

Images were scored according to the AS spinal MRI activity (ASspiMRI-a) score, ${ }^{30} 31$ a widely used MRI scoring system, recently validated in a multi-reader exercise. ${ }^{32} 33$ With the ASspiMRI-a score, activity is assessed at the level of the discovertebral unit (DVU). A DVU is defined as the area between two virtual horizontal lines through the middle of two adjacent vertebrae. The combined information provided by T1/Gd-DTPA and STIR sequences was used for scoring the MR images and each DVU was given an MRI activity score based on the amount of $\mathrm{BMO}$ or erosions, as follows: $0=$ no abnormalities, $1=$ minor $\mathrm{BMO}$ involving $\leq 25 \%$ of the DVU; $2=$ moderate $\mathrm{BMO}$ involving $>25 \%$ but $\leq 50 \%$ of the DVU; $3=$ major $\mathrm{BMO}$ involving $>50 \%$ of the DVU; $4=\mathrm{BMO}$ and minor erosion involving $\leq 25 \%$ of the DVU; $5=\mathrm{BMO}$ and moderate erosion involving $>25 \%$ but $\leq 50 \%$ of the DVU; $6=\mathrm{BMO}$ and major erosion involving $>50 \%$ of the DVU. Thus, the ASspiMRI-a score for each DVU ranges from 0 to 6. Since 23 DVUs are assessed (from C2 to S1), the total ASspiMRI-a score for the spine ranges from 0 to 138. In studies concerning the ASspiMRI-a score, no description has been given as to how missing DVU scores should be handled. In this study, we chose to exclude patients who had $>2$ DVU scores missing; if $\leq 2$ DVU scores were missing, the mean of the other DVU scores was used for imputation. Two qualified and welltrained readers, different from the readers of the radiographs, who were blinded to the patient's identity and treatment evaluated each sequence independently. The mean of both readers' scores was used in the analysis.

\section{Statistical analysis}

All data are expressed as median (IOR) or proportion if applicable. Simple univariate correlations were calculated on baseline values using Spearman rank correlation. Independent associations between the variables of interest were investigated by linear regression analysis, using BASMI as the dependent variable. The relationship between spinal mobility as measured by the BASMI, MRI inflammation as assessed by the ASspiMRI-a score and structural damage according to the mSASSS was first investigated. Second, the contributory or confounding effect of other independent variables was investigated one by one: disease activity as assessed by the ASDAS or the BASDAI, CRP, disease duration, age, gender, body mass index and HLA-B27 status. Finally, a best-fit model with the relevant variables was built. Non-normally distributed variables (mSASSS, ASspiMRI-a score, CRP and disease duration) underwent a normalisation procedure using the van der Waerden technique before being entered into the linear regression analysis. Interactions between mSASSS, ASspiMRI-a, CRP, age, disease duration and gender were tested. Because of a relevant statistical interaction between disease duration and ASspiMRI-a/mSASSS, a subanalysis was performed for patients with low ( $\leq 3$ years) versus high ( $>3$ years) disease duration (the 3 -year cut-off point corresponding to the first quartile). All the statistical analyses were performed using SPSS 16 (SPSS, USA).

\section{RESULTS}

\section{Baseline clinical, imaging and demographic characteristics of the study population}

We analysed data of 214 patients, for whom all baseline variables were available. Table 1 shows the baseline clinical, imaging and 
Table 1 Summary of the baseline clinical, imaging and demographic characteristics of the study population $(n=214)^{*}$

\begin{tabular}{|c|c|}
\hline Characteristics & Value \\
\hline Male (n (\%)) & $168(78.5)$ \\
\hline Age (years) & $40(32,46)$ \\
\hline Disease duration (years) & $9(3,16)$ \\
\hline $\mathrm{BMI}\left(\mathrm{kg} / \mathrm{m}^{2}\right)$ & $25.5(22.6,27.9)$ \\
\hline History of uveitis (n (\%)) & $135(63.1)$ \\
\hline History of psoriasis (n (\%)) & $20(9.3)$ \\
\hline History of IBD (n (\%)) & $15(7.0)$ \\
\hline HLA-B27 positive (n (\%))† & $191(89.7)$ \\
\hline BASMI & $4.6(3.6,5.8)$ \\
\hline ASDAS & $4.0(3.4,4.6)$ \\
\hline BASDAI & $6.5(5.3,7.0)$ \\
\hline CRP level (mg/dl)‡ & $1.5(0.7,2.9)$ \\
\hline mSASSS & $13.8(4.5,29.1)$ \\
\hline ASspiMRI-a & $4.5(0.5,9.8)$ \\
\hline
\end{tabular}

*Except were indicated otherwise, values are the median (IQR); tone patient was not assessed for HLA-B27 status; 价ormal range $0-0.5 \mathrm{mg} / \mathrm{dl}$.

ASDAS, Ankylosing Spondylitis Disease Activity Score; ASspiMRI-a, Ankylosing Spondylitis spinal MRI activity; BASDAl, Bath Anklyosing Spondylitis Disease Activity Index; BASMI, linear definition of the Bath Ankylosing Spondylitis Metrology Index; BMI, body mass index; CRP, C-reactive protein; IBD, inflammatory bowel disease; mSASSS, modified Stoke Ankylosing Spondylitis Spine Score.

demographic characteristics of the study population. The study population was typical of patients with moderate-to-severe AS. Most patients were men $(78.5 \%)$ and were HLA-B27 positive $(89.7 \%)$. At baseline, $79.9 \%$ of the patients had elevated CRP levels (CRP $>0.5 \mathrm{mg} / \mathrm{dl}$ ), $82.2 \%$ of the patients had evidence of spinal inflammation (ASspiMRI-a score $>0$ by any reader) and $98.6 \%$ of the patients had evidence of radiographic damage of the spine (mSASSS $>0$ by any reader).

\section{Relationship between spinal mobility, radiographic damage of the spine and spinal inflammation}

BASMI correlated moderately well with mSASSS (Spearman's $\rho=0.6, p<0.001)$ and weakly with ASspiMRI-a $(\rho=0.3, p<0.001)$, disease duration $(\rho=0.3, p<0.001), \operatorname{CRP}(\rho=0.2, p=0.006)$ and age $(\rho=0.2, p=0.001)$. Multivariate linear regression analysis showed that the mSASSS and ASspiMRI-a scores were independently associated with BASMI (table 2, model 1). We further investigated whether the association between spinal mobility, radiographic damage of the spine and spinal inflammation was independent of differences in clinical and demographic variables (table 2 , models 2-9). The regression coefficient (B) for the relationship between BASMI and mSASSS $(B=0.841 ; p<0.001)$ and for the relationship between BASMI and ASspiMRI-a $(B=0.213$; $\mathrm{p}=0.031)$ was only significantly influenced by adding gender to the model $(>10 \%$ change in the value of $\mathrm{B}$ ). A best-fit model for BASMI (table 3 ) included mSASSS $(B=0.865 ; p<0.001)$, ASspiMRI-a $(B=0.236$; $p=0.018)$ and gender $(B=-0.305 ; p=0.165)$. Results were similar if disease duration (almost significant in the exploratory analysis shown in table 2) was included in the model: mSASSS $(B=0.809$; $p<0.001)$, ASspiMRI-a $(B=0.244 ; p=0.014)$, disease duration $(B=0.171 ; p=0.065)$ and gender $(B=-0.275 ; p=0.210)$. Of note, the analysis using the untransformed variables produced similar results to the analysis with normalised variables, which adds to the robustness of the results (data not shown). Figure 1 plots the relationship between spinal mobility and radiographic damage of the spine for three different preset values of spinal inflammation (Figure 1A) and the relationship between spinal mobility and spinal inflammation for three different preset values of radiographic damage of the spine (Figure $1 \mathrm{~B}$ ), using the regression equation obtained from the untransformed data. From the graphs, it is clear that both mSASSS and ASspiMRI-a are independently determining the value of BASMI.

Owing to a relevant statistical interaction, patients were then separated according to disease duration (table 3). In patients with a disease duration $\leq 3$ years, B was greater for ASspiMRI-a than for mSASSS (0.595 vs 0.380), while in patients with a disease duration $>3$ years, $\mathrm{B}$ was greater for mSASSS than for ASspiMRI-a (0.924 vs 0.156).

\section{DISCUSSION}

The results of this study show that spinal mobility impairment in AS is independently determined by irreversible spinal damage as well as by reversible spinal inflammation. These findings are consistent with clinical data reporting the improvement of both spinal inflammation and spinal mobility after treatment with anti-TNF $\alpha^{13-15}$ and with studies confirming the association between radiographic damage of the spine and spinal mobility impairment at the group level ${ }^{8-12}$ but not always at the individual level. ${ }^{12}$ It confirms that spinal inflammation may explain those cases of discordance between the level of spinal mobility impairment and the degree of radiographic damage.

Moreover, the results of this study also show that spinal mobility impairment is more influenced by spinal inflammation in early disease, and by structural damage in later disease, which may imply that spinal mobility can better be maintained by early as compared with delayed intervention.

To our knowledge, only one study has assessed the relationship between MRI spinal inflammation and spinal mobility. Rudwaleit et $a^{\beta 4}$ reported a Spearman $r$ coefficient of 0.238 between the Berlin MRI spine score ${ }^{19}$ and the BASMI. This correlation coefficient was not statistically significant, which may be owing to the small sample size of the study (46 patients with active AS who participated in randomised controlled trials). In the same study, the authors reported that the MRI scores of the spine did not correlate at all with other disease activity markers, including BASDAI, patient global, morning stiffness, CRP and erythrocyte sedimentation rate. However, this study also showed that widespread inflammation in the spine as detected by MRI contributes to predicting a major clinical response in patients with active AS treated with anti-TNF $\alpha$ agents.

Owing to its ability to detect inflammatory changes, and in light of the paucity of reliable objective measures to quantify disease activity in AS, MRI has been increasingly used as a surrogate end point in clinical trials of TNFo-blocking agents. MRI has also evolved as an important diagnostic tool in patients without definite radiographic sacroiliitis, because it visualises active (acute) inflammation in the sacroiliac joints and the spine and may therefore be a relevant tool for the early diagnosis of axial spondyloarthritis (SpA), including AS. ${ }^{35} 36$ By showing that inflammatory changes (and not only structural changes) contribute to spinal mobility impairment, this study gives a new and original meaning to MRI spinal inflammation, further elucidating its role in the burden of disease.

Most likely, spinal inflammation prevails in the early phase of AS, whereas at later stages, the disease burden is often caused both by inflammatory and secondary changes. Given that antiTNF $\alpha$ therapy is highly anti-inflammatory and effective in the long-term suppression of active spinal inflammation as seen on MRI, ${ }^{16-19}$ the finding that spinal mobility impairment is more influenced by spinal inflammation in early disease supports the 


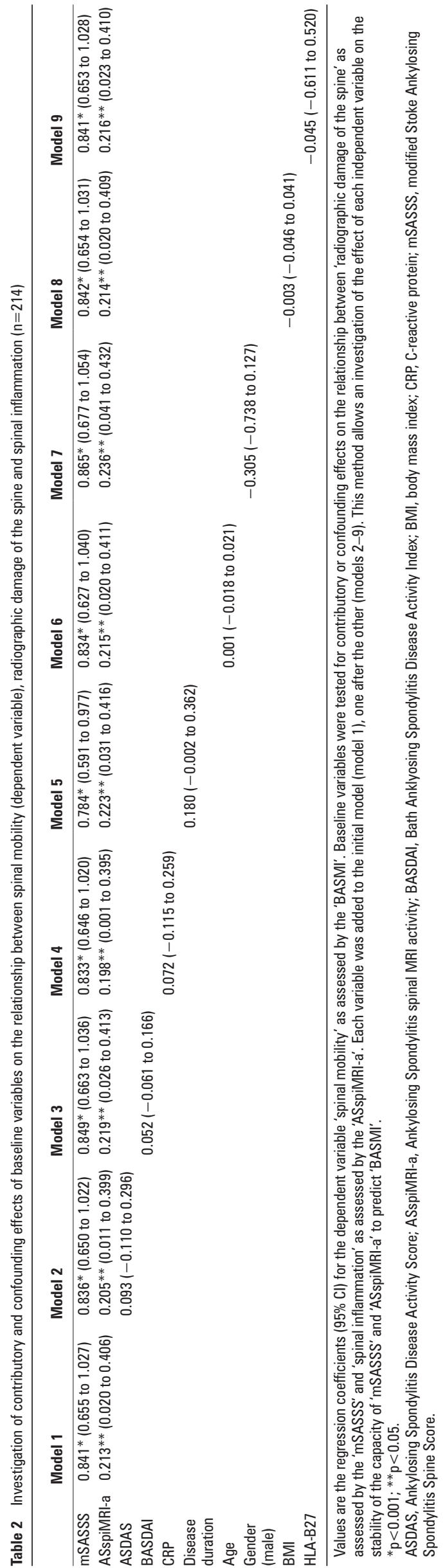

Table 3 Best-fit model for spinal mobility (BASMI).

\begin{tabular}{|c|c|c|c|}
\hline & $\begin{array}{l}\text { Entire ankylosing } \\
\text { spondylitis } \\
\text { population } \\
\text { (n=214) }\end{array}$ & $\begin{array}{l}\text { Disease duration } \\
\leq 3 \text { years }(n=53)\end{array}$ & $\begin{array}{l}\text { Disease } \\
\text { duration } \\
>3 \text { years } \\
(n=161)\end{array}$ \\
\hline \multicolumn{4}{|l|}{ mSASSS } \\
\hline B & 0.865 & 0.380 & 0.924 \\
\hline $95 \% \mathrm{Cl}$ & $0.677-1.054$ & -0.099 to 0.858 & $0.715-1.134$ \\
\hline p Value & $<0.001$ & 0.117 & $<0.001$ \\
\hline \multicolumn{4}{|c|}{ ASspiMRI-a } \\
\hline B & 0.236 & 0.595 & 0.156 \\
\hline $95 \% \mathrm{Cl}$ & $0.041-0.432$ & $0.173-1.016$ & -0.070 to 0.383 \\
\hline $\mathrm{p}$ Value & 0.018 & 0.007 & 0.174 \\
\hline \multicolumn{4}{|c|}{ Gender (male) } \\
\hline B & -0.305 & -0.454 & -0.299 \\
\hline $95 \% \mathrm{Cl}$ & -0.738 to 0.127 & -1.338 to 0.429 & -0.796 to 0.198 \\
\hline $\mathrm{p}$ Value & 0.165 & 0.307 & 0.237 \\
\hline
\end{tabular}

Results are shown for the entire AS population and according to disease duration. ASspiMRI-a, Ankylosing Spondylitis spinal MRI activity; B, regression coefficient; BASMI, linear definition of the Bath Ankylosing Spondylitis Metrology Index; mSASSS, modified Stoke Ankylosing Spondylitis Spine Score.

concept of a 'window of opportunity' to treat patients before they develop irreversible bony changes and suggests that early treatment of reversible inflammatory lesions may be of great importance in recovering mobility and achieving better patient outcomes. The relationship between ankylosis and spinal inflammation is still a matter of debate. In fact, there is now evidence that anti-TNF $\alpha$ therapy will not influence radiographic progression in patients with established AS. ${ }^{37} 38$ Irrespective of this relationship, the findings from this study have immediate implications for patient care and patient outcome, since they show a relationship between spinal inflammation and spinal mobility, which, in turn, has direct implications for the function and quality of life..$^{39}$ Ultimately, the findings from this study may also be of relevance to a group of patients with a substantial disease burden but unmet need: the patients with non-radiographic axial SpA, ${ }^{41}$ for whom the recent publication of validated classification criteria for axial SpA ${ }^{35} 36$ will facilitate the conduct of clinical trials and observational studies. In addition, the finding that in established disease spinal mobility is mainly explained by structural damage indicates that spinal mobility can also be seen as a surrogate measure for long-term outcome. The 3-year cut-off point used in this study is arbitrary and should not be used as a reference value. Moreover, spinal inflammation cannot be neglected in later disease as many of these patients have significant spinal inflammation. Furthermore, the benefit of antiTNF $\alpha$ therapy in later disease is indisputable and goes beyond the reduction of spinal inflammation and improvement of spinal mobility.

Some limiting factors should be taken into account. One of them may be the fact that mSASSS only accounts for structural damage in the anterior corners of the cervical and lumbar spine. Exclusion of the thoracic spine and of the posterior sites of the spine may result in an underestimation of the structural damage, as may the exclusion of the vertebral ligaments and facet joints, which also have an important role in spinal mobility. This study, however, gives justice to the hypothesis that involvement of the structures not measured directly by mSASSS is in line with structures measured by mSASSS. Another limiting factor may be the fact that the ASspiMRI-a score only captures spinal inflammatory activity (bone oedema and discitis) at the DVU level, excluding the surrounding 

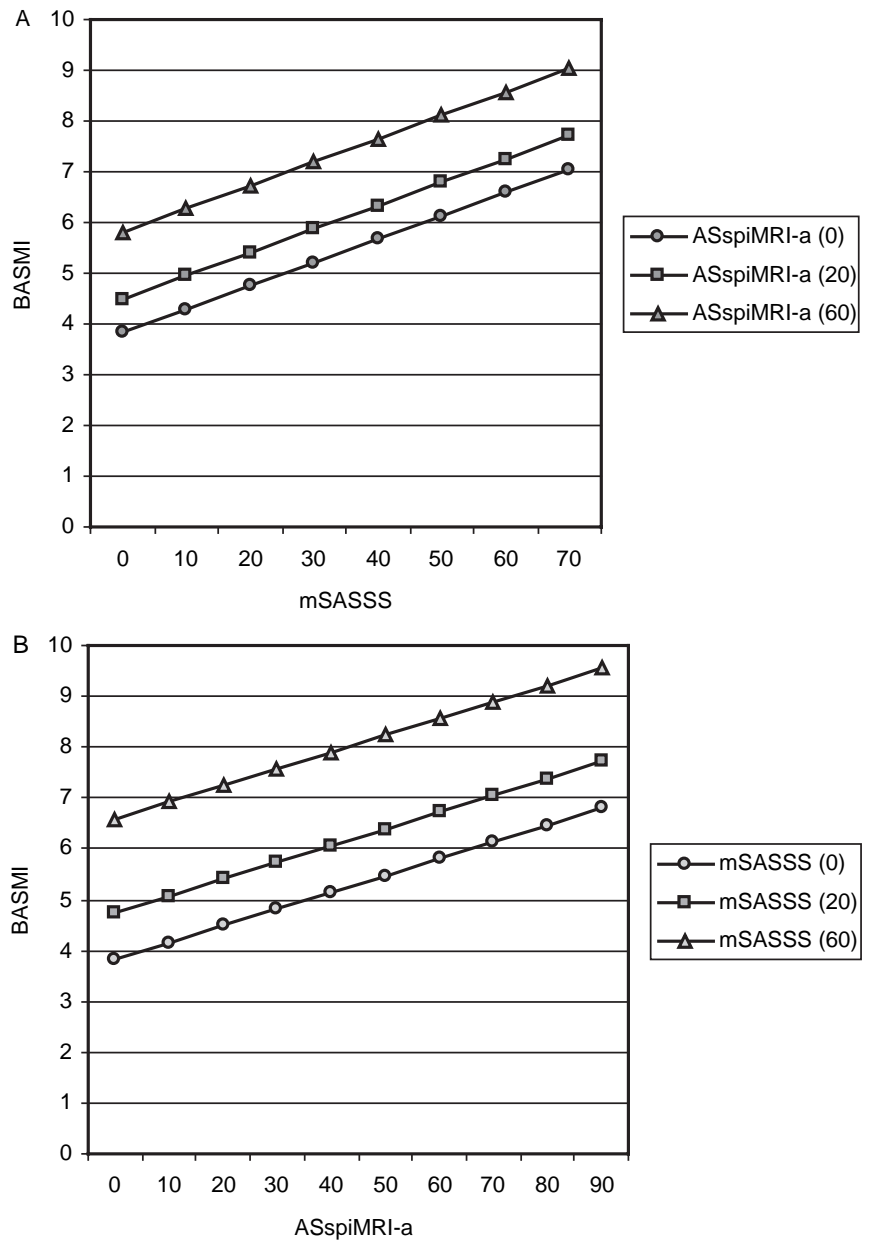

Figure 1 (A) Relationship between spinal mobility and radiographic damage of the spine for three different preset values of spinal inflammation; (B) relationship between spinal mobility and spinal inflammation for three different preset values of radiographic damage of the spine. An increase of 10 units in mSASSS (range 0-72) leads to an increase of 0.46 in BASMI (range $0-10$ ) independent of the effect of ASspiMRI-a; similarly, an increase of 10 units in ASspiMRI-a (range $0-138$ ) leads to an increase of 0.33 in BASMI. ASspiMRI-a, ankylosing spondylitis spinal MRI activity; BASMI, linear definition of the Bath Ankylosing Spondylitis Metrology Index; mSASSS, modified Stoke Ankylosing Spondylitis Spine Score.

soft tissues and facet joints, which may underestimate inflammatory activity. However, none of the other available scoring methods for structural damage or spinal inflammation performs better than the mSASSS and ASspiMRI-a, ${ }^{29} 32$ respectively, and it is unlikely that this can influence the overall conclusions of this study, although at the individual level it may be of some importance. The above arguments would be mainly of importance if we did not establish a relationship. Another theoretical limitation pertains to lack of generalisability, or that the results of this study are only valid within the ASSERT population. However, we do not believe that external validity is compromised because the population includes the entire range of spinal mobility impairment, radiographic damage and spinal inflammation.

In summary, this study suggests that both the assessment of MRI spinal inflammation and radiographic damage of the spine have an independent and additive value in the outcome measurement of AS, both contributing to spinal mobility impairment. This study also suggest that spinal mobility impairment is more influenced by spinal inflammation in early disease, and by structural damage in later disease, which may imply that spinal mobility can better be maintained by early rather than late intervention.

Acknowledgements We thank Benjamin Hsu for his critical review of the manuscript. We also thank Centocor and Schering-Plough for providing us with the ASSERT database, which allowed us to do the analyses necessary to write this manuscript.

Funding PM was supported by the Fundação para a Ciência e Tecnologia grant SFRH/BD/62329/2009 (Fundação para a Ciência e a Tecnologia, Loja do Cientista, Av D Carlos I, 124 J, 1249-074 Lisbon, Portugal). The ASSERT trial (Arthritis Rheum 2005;52:582-91) was supported by Centocor, Inc, Malvern, Pennsylvania, USA

Competing interests None.

Ethics approval Ethics committee approval was secured for the ASSERT trial (Arthritis Rheum 2005;52:582-91). This study is an investigator-preformed subanalysis of the ASSERT cohort.

Provenance and peer review Not commissioned; externally peer reviewed.

Contributors All authors included in the manuscript fulfil the criteria of authorship. There is no one else fulfilling the criteria who has not been included as an author.

\section{REFERENCES}

1. Braun J, Sieper J. Ankylosing spondylitis. Lancet 2007;369:1379-90.

2. Braun J, Bollow M, Eggens U, et al. Use of dynamic magnetic resonance imaging with fast imaging in the detection of early and advanced sacroilititis in spondylarthropathy patients. Arthritis Rheum 1994;37:1039-45

3. Braun J, Bollow M, Sieper J. Radiologic diagnosis and pathology of the spondyloarthropathies. Rheum Dis Clin North Am 1998;24:697-735.

4. Bollow M, Braun J, Hamm B, et al. Early sacroilititis in patients with spondyloarthropathy: evaluation with dynamic gadolinium-enhanced MR imaging. Radiology 1995; 194:529-36.

5. Hermann KG, Landewé RB, Braun J, et al. Magnetic resonance imaging of inflammatory lesions in the spine in ankylosing spondylitis clinical trials: is paramagnetic contrast medium necessary? J Rheumatol 2005;32:2056-60.

6. Bollow M, Enzweiler C, Taupitz M, et al. Use of contrast enhanced magnetic resonance imaging to detect spinal inflammation in patients with spondyloarthritides. Clin Exp Rheumatol 2002;20(Suppl 28):S167-74.

7. Hermann KG, Althoff CE, Schneider U, et al. Spinal changes in patients with spondyloarthritis: comparison of MR imaging and radiographic appearances. Radiographics 2005;25:559-69; discussion 569-70.

8. Kennedy LG, Jenkinson TR, Mallorie PA, et al. Ankylosing spondylitis: the correlation between a new metrology score and radiology. Br J Rheumatol 1995;34:767-70.

9. Viitanen JV, Kokko ML, Lehtinen K, et al. Correlation between mobility restrictions and radiologic changes in ankylosing spondylitis. Spine 1995;20:492-6.

10. Viitanen JV, Kokko ML, Heikkilä S, et al. Neck mobility assessment in ankylosing spondylitis: a clinical study of nine measurements including new tape methods for cervical rotation and lateral flexion. Br J Rheumatol 1998;37:377-81.

11. Spoorenberg A, van der Heijde D, de Klerk E, et al. Relative value of erythrocyte sedimentation rate and $\mathrm{C}$-reactive protein in assessment of disease activity in ankylosing spondylitis. J Rheumatol 1999;26:980-4.

12. Wanders $\mathbf{A}$, Landewé $R$, Dougados $M$, et al. Association between radiographic damage of the spine and spinal mobility for individual patients with ankylosing spondylitis: can assessment of spinal mobility be a proxy for radiographic evaluation? Ann Rheum Dis 2005;64:988-94.

13. van der Heijde D, Kivitz A, Schiff MH, et al. Efficacy and safety of adalimumab in patients with ankylosing spondylitis: results of a multicenter, randomized, doubleblind, placebo-controlled trial. Arthritis Rheum 2006;54:2136-46.

14. van der Heijde D, Dijkmans B, Geusens P, et al. Efficacy and safety of infliximab in patients with ankylosing spondylitis: results of a randomized, placebo-controlled trial (ASSERT). Arthritis Rheum 2005;52:582-91.

15. Davis JC Jr, Van Der Heijde D, Braun J, et al. Recombinant human tumor necrosis factor receptor (etanercept) for treating ankylosing spondylitis: a randomized, controlled trial. Arthritis Rheum 2003;48:3230-6.

16. Braun J, Landewé R, Hermann KG, et al. Major reduction in spinal inflammation in patients with ankylosing spondylitis after treatment with infliximab: results of a multicenter, randomized, double-blind, placebo-controlled magnetic resonance imaging study. Arthritis Rheum 2006;54:1646-52.

17. Baraliakos X, Davis J, Tsuji W, et al. Magnetic resonance imaging examinations of the spine in patients with ankylosing spondylitis before and after therapy with the tumor necrosis factor alpha receptor fusion protein etanercept. Arthritis Rheum 2005;52:1216-23.

18. Baraliakos X, Brandt J, Listing J, et al. Outcome of patients with active ankylosing spondylitis after two years of therapy with etanercept: clinical and magnetic resonance imaging data. Arthritis Rheum 2005;53:856-63. 
19. Haibel H, Rudwaleit M, Brandt $\mathrm{HC}$, et al. Adalimumab reduces spinal symptoms in active ankylosing spondylitis: clinical and magnetic resonance imaging results of a fifty-two-week open-label trial. Arthritis Rheum 2006;54:678-81.

20. van der Linden $\mathbf{S}$, Valkenburg HA, Cats A. Evaluation of diagnostic criteria for ankylosing spondylitis. A proposal for modification of the New York criteria. Arthritis Rheum 1984;27:361-8.

21. Jenkinson TR, Mallorie PA, Whitelock HC, et al. Defining spinal mobility in ankylosing spondylitis (AS). The Bath AS Metrology Index. J Rheumatol 1994:21:1694-8.

22. Jones SD, Porter J, Garrett SL, et al. A new scoring system for the Bath Ankylosing Spondylitis Metrology Index (BASMI). J Rheumatol 1995;22:1609.

23. Zochling J, Sieper J, van der Heijde D, et al. Development of a core set of domains for data collection in cohorts of patients with ankylosing spondylitis receiving antitumor necrosis factor-alpha therapy. J Rheumatol 2008;35:1079-82.

24. van der Heijde D, Landewé R, Feldtkeller E. Proposal of a linear definition of the Bath Ankylosing Spondylitis Metrology Index (BASMI) and comparison with the 2-step and 10-step definitions. Ann Rheum Dis 2008;67:489-93.

25. Garrett S, Jenkinson T, Kennedy LG, et al. A new approach to defining disease status in ankylosing spondylitis: the Bath Ankylosing Spondylitis Disease Activity Index. J Rheumatol 1994;21:2286-91.

26. Lukas C, Landewé R, Sieper J, et al. Development of an ASAS-endorsed disease activity score (ASDAS) in patients with ankylosing spondylitis. Ann Rheum Dis 2009;68:18-24.

27. Creemers MC, Franssen MJ, van't Hof MA, et al. Assessment of outcome in ankylosing spondylitis: an extended radiographic scoring system. Ann Rheum Dis 2005; 64:127-9

28. van der Heijde D, Landewé R. Selection of a method for scoring radiographs for ankylosing spondylitis clinical trials, by the Assessment in Ankylosing Spondylitis Working Group and OMERACT. J Rheumatol 2005;32:2048-9.

29. Wanders AJ, Landewé RB, Spoorenberg A, et al. What is the most appropriate radiologic scoring method for ankylosing spondylitis? A comparison of the available methods based on the Outcome Measures in Rheumatology Clinical Trials filter. Arthritis Rheum 2004;50:2622-32.

30. Braun J, Baraliakos X, Golder W, et al. Magnetic resonance imaging examinations of the spine in patients with ankylosing spondylitis, before and after successful therapy with infliximab: evaluation of a new scoring system. Arthritis Rheum 2003;48:1126-36.

31. Braun J van der Heijde D. Imaging and scoring in ankylosing spondylitis. Best Pract Res Clin Rheumatol 2002;16:573-604.

32. Lukas C, Braun J, van der Heijde D, et al. Scoring inflammatory activity of the spine by magnetic resonance imaging in ankylosing spondylitis: a multireader experiment. J Rheumatol 2007;34:862-70.

33. van der Heijde D, Landewé R, Hermann KG, et al. Is there a preferred method for scoring activity of the spine by magnetic resonance imaging in ankylosing spondylitis? J Rheumatol 2007;34:871-3.

34. Rudwaleit M, Schwarzlose S, Hilgert ES, et al. MRI in predicting a major clinical response to anti-tumour necrosis factor treatment in ankylosing spondylitis. Ann Rheum Dis 2008;67:1276-81.

35. Rudwaleit M, Landewé R, van der Heijde D, et al. The development of Assessment of SpondyloArthritis international Society classification criteria for axial spondyloarthritis (part I): classification of paper patients by expert opinion including uncertainty appraisal. Ann Rheum Dis 2009;68:770-6.

36. Rudwaleit M, van der Heijde D, Landewé R, et al. The development of Assessment of SpondyloArthritis international Society classification criteria for axial spondyloarthritis (part II): validation and final selection. Ann Rheum Dis 2009;68:777-83.

37. van der Heijde D, Landewé $R$, Baraliakos $X$, et al. Radiographic findings following two years of infliximab therapy in patients with ankylosing spondylitis. Arthritis Rheum 2008;58:3063-70.

38. van der Heijde D, Landewé R, Einstein S, et al. Radiographic progression of ankylosing spondylitis after up to two years of treatment with etanercept. Arthritis Rheum 2008;58:1324-31.

39. Machado P, van der Heijde D, Braun J, et al. Both clinical disease activity and spinal mobility contribute to physical function in patients with ankylosing spondylitis. Ann Rheum Dis 2009;68(Suppl 3):753.

40. Machado $\mathbf{P}$, Landewé R, Braun J, et al. Health related quality of life (physical component) in ankylosing spondylitis is independently determined both by disease activity and by physical function. Ann Rheum Dis 2009;68(Suppl 3):646.

41. Rudwaleit M, Haibel H, Baraliakos X, et al. The early disease stage in axial spondylarthritis: results from the German Spondyloarthritis Inception Cohort. Arthritis Rheum 2009;60:717-27. 


\section{ARD}

\section{Both structural damage and inflammation of the spine contribute to impairment of spinal mobility in patients with ankylosing spondylitis}

Pedro Machado, Robert Landewé, Jürgen Braun, et al.

Ann Rheum Dis 2010 69: 1465-1470 originally published online May 24, 2010

doi: 10.1136/ard.2009.124206

Updated information and services can be found at:

http://ard.bmj.com/content/69/8/1465.full.html

These include:

References This article cites 41 articles, 10 of which can be accessed free at: http://ard.bmj.com/content/69/8/1465.full.html\#ref-list-1

Article cited in:

http://ard.bmj.com/content/69/8/1465.full.html\#related-urls

Email alerting Receive free email alerts when new articles cite this article. Sign up in service the box at the top right corner of the online article.

Notes

To request permissions go to:

http://group.bmj.com/group/rights-licensing/permissions

To order reprints go to:

http://journals.bmj.com/cgi/reprintform

To subscribe to BMJ go to:

http://group.bmj.com/subscribe/ 